University of Wollongong

Research Online

Faculty of Engineering and Information

Faculty of Engineering and Information

Sciences - Papers: Part A

Sciences

$1-1-2015$

Community energy storage for neutral voltage rise mitigation in four-wire multigrounded LV feeders with unbalanced solar PV allocation

Md Jan E Alam

University of Queensland, mjealam@uowmail.edu.au

Kashem M. Muttaqi

University of Wollongong, kashem@uow.edu.au

Danny Sutanto

University of Wollongong, soetanto@uow.edu.au

Follow this and additional works at: https://ro.uow.edu.au/eispapers

Part of the Engineering Commons, and the Science and Technology Studies Commons

Research Online is the open access institutional repository for the University of Wollongong. For further information contact the UOW Library: research-pubs@uow.edu.au 


\title{
Community energy storage for neutral voltage rise mitigation in four-wire multigrounded LV feeders with unbalanced solar PV allocation
}

\author{
Abstract \\ The traditional neutral voltage problem in low-voltage (LV) four-wire multigrounded distribution networks \\ can be aggravated due to an unbalanced allocation of one-phase photovoltaic (PV) units. Inherent \\ limitations restrict the performance of the traditional strategies to mitigate the combined effect of load \\ and PV unbalance. To overcome the shortcoming of traditional approaches, a new dynamic mitigation \\ approach using community energy storage (CES) is proposed in this paper. A power balancing algorithm \\ is developed to perform the balancing operation while minimizing power drawn from the CES. A charge/ \\ discharge control strategy is developed that will continuously balance and dynamically adjust the power \\ exchange with the grid in a real time, and mitigate the neutral current and neutral voltage rise. To \\ investigate the applicability of the proposed approach under physical time delays associated with battery \\ and PV systems, a suitable dynamic model is developed. An Australian LV distribution system is used to \\ verify the proposed approach under daylong variations of load and PV, and also during short-term \\ variations of PV output caused by cloud passing.

\section{Keywords} \\ four, multigrounded, allocation, pv, unbalanced, community, solar, storage, neutral, voltage, rise, mitigation, \\ feeders, Iv, wire, energy \\ Disciplines \\ Engineering | Science and Technology Studies \\ Publication Details \\ M. J E. Alam, K. M. Muttaqi \& D. Sutanto, "Community energy storage for neutral voltage rise mitigation in \\ four-wire multigrounded LV feeders with unbalanced solar PV allocation," IEEE Transactions on Smart \\ Grid, vol. 6, (6) pp. 2845-2855, 2015.
}




\title{
Community Energy Storage for Neutral Voltage Rise Mitigation in 4-wire Multigrounded LV Feeders with Unbalanced Solar PV Allocation
}

\author{
M. J. E. Alam, Member, IEEE, K. M. Muttaqi, Senior Member, IEEE and D. Sutanto, Senior Member, \\ IEEE
}

\begin{abstract}
The traditional neutral voltage problem in low voltage (LV) 4-wire multigrounded distribution networks can be aggravated due to an unbalanced allocation of 1-phase photovoltaic (PV) units. Inherent limitations restrict the performance of the traditional strategies to mitigate the combined effect of load and PV unbalance. To overcome the shortcoming of traditional approaches, a new dynamic mitigation approach using community energy storage (CES) is proposed in this paper. A power balancing algorithm is developed to perform the balancing operation while minimizing power drawn from the CES. A charge/discharge control strategy is developed that will continuously balance and dynamically adjust the power exchange with the grid in a real time and mitigate the neutral current and neutral voltage rise. To investigate the applicability of the proposed approach under physical time delays associated to battery and PV systems, a suitable dynamic model is developed. An Australian LV distribution system is used to verify the proposed approach under daylong variations of load and PV, and also during short term variations of PV output caused by cloud passing.
\end{abstract}

Index Terms-- Solar PV, 4-wire multigrounded LV network, neutral current, neutral voltage rise, community energy storage.

\section{NOMENCLATURE}

$\begin{array}{ll}i, p, k & \begin{array}{l}\text { Index for bus, phase, and time instant, } \\ \text { respectively. }\end{array} \\ P_{\mathrm{L}}^{i p}, P_{\mathrm{PV}}^{i p} & \begin{array}{l}\text { Load and PV inverter active power at the } i \text { - } \\ \text { th bus, } p \text {-th phase. }\end{array} \\ Q_{\mathrm{L}}^{i p}, Q_{\mathrm{PV}}^{i p} & \begin{array}{l}\text { Load and PV inverter reactive power at the } \\ i \text {-th bus, } p \text {-th phase. }\end{array} \\ P_{\mathrm{B}}^{i p} & \begin{array}{l}\text { Active power of any local battery at the } i \text { - } \\ \text { th bus, } p \text {-th phase. }\end{array} \\ P_{\mathrm{CES}}^{i p} & \begin{array}{l}\text { Active power of local battery at the } i \text {-th } \\ \text { bus, } p \text {-th phase. }\end{array} \\ P_{\text {grid }}^{i p} & \begin{array}{l}\text { Active power exchange with grid at the } i \text { - } \\ \text { th bus, } p \text {-th phase. }\end{array} \\ P_{\text {grid }}^{\text {ref } i} & \text { The reference active power exchange with } \\ \text { grid at the } i \text {-th bus for balancing operation. }\end{array}$

This work is supported by the Australian Research Council (ARC) and Essential Energy Linkage Grant, LP100100618.

M. J. E. Alam is with Global Change Institute, The University of Queensland, QLD 4072, Australia (e-mail: mjea982@uowmail.edu.au, m.alam8@uq.edu.au). K. M. Muttaqi and D. Sutanto is with Australian Power Quality and Reliability Center, School of Electrical Computer and Telecommunications Engineering, University of Wollongong, NSW 2522, Australia (e-mail: kashem@uow.edu.au, soetanto@uow.edu.au).

$V_{\mathrm{re}}^{i p}, V_{\mathrm{im}}^{i p}$
$V_{\mathrm{re}}^{i n}, V_{\mathrm{im}}^{i n}$
$I_{\mathrm{N}}, I_{\mathrm{NG}}, I_{\mathrm{NC}}$
$I_{\mathrm{CES}}, V_{\mathrm{CES}}$
$\mathrm{SoC}, C_{\mathrm{CES}}$
$\mathbf{p}$
$x_{\mathrm{CES}}, T_{\mathrm{CES}}$,
$P_{\mathrm{CES}-\mathrm{ref}}$
$x_{\mathrm{PI}}, k_{\mathrm{P}}, k_{\mathrm{I}}$
$x_{\mathrm{D} 1}^{i p}, x_{\mathrm{D} 2}^{i p}$,
$T_{\mathrm{D} 1}^{i p}, T_{\mathrm{D} 2}^{i p}$
$x_{\mathrm{INV}}^{i p}, T_{\mathrm{INV}}^{i p}$
$\eta_{\mathrm{INV}}^{i p}$
$P_{\mathrm{DC}}^{i p}$

Real and imaginary part of the phase voltage at the $i$-th bus and $p$-th phase. Real and imaginary part of the neutral voltage at the $i$-th bus and $p$-th phase. Neutral current, neutral to ground current and neutral conductor current. CES battery current and voltage. CES battery state of Charge and Capacity. A set of modeling parameters for CES. Power output, time constant of CES and the reference power for controlling CES. PI controller output, and PI controller proportional and integral gains Outputs and time constants of the DC/DC converters in the PV inverter at the $i$-th bus and $p$-th phase.

Output, time constant and efficiency of the $\mathrm{PV}$ inverter at the $i$-th bus and $p$-th phase.

PV panel DC power of the PV inverter system at the $i$-th bus and $p$-th phase.

\section{INTRODUCTION}

$\mathrm{T}$ HE existence of neutral current flow in low voltage (LV) 4-wire multigrounded distribution feeders due to load [1] and line impedance unbalance is well-known in the distribution system engineering discipline. The traditional neutral current problem is worsening with an unbalanced allocation of numerous rooftop PV units at the LV distribution level [2]. Studies on PV penetration trends in the power industry in USA [3], Europe [4], and Australia [5] show that high PV penetration is already a concern because of its impact on the network operation including voltage rise [6] and protection issues [7], and therefore, investigations are being conducted to determine the maximum PV penetration level [8]. The rise of neutral voltage caused by the flow of neutral current through neutral grounding impedances is a significant manifestation of the increased neutral current caused by the combined effect of load and PV unbalance. Distribution utilities in Australia have already expressed the concern of neutral voltage rise due to unbalanced allocation of singlephase solar PV units in LV feeders. It is also reported in [9] that the neutral grounding impedances can increase due to bonding of the earth wire with a non-metallic water piping system. In such as a case, the Neutral-to-Ground Voltage 
(NGV) problem can further deteriorate. A high $\mathrm{NGV}$ value can damage sensitive electronic and computing equipment due to the common-mode noise effect [10]. Manufacturers of computing equipment have specified $0.5 \mathrm{~V}$ [10] as the limit of common-mode noise; a more stringent limit of $0.1 \mathrm{~V}$ is reported in [11]. NGV and other forms of stray voltages are also detrimental for human beings [12] and farm animals [13]. To ensure a safe and reliable operation of distribution networks, neutral current and NGV rise have to be treated with due importance.

A number of methods for the mitigation of neutral current and neutral voltage rise have been reported in the literature [13-17]. Load balancing [14, 15, 17] is a well-known traditional mitigation strategy where the customer connections are reconfigured to achieve a more balanced distribution of the loads. However, in practice it is very difficult to achieve a perfect balancing of the loads throughout the feeder. Re-sizing of neutral conductor $[14,17]$, improvement of the grounding system [14, 17], installation of equipotential planes [13, 14, $16]$ are some other forms of traditional mitigation techniques, which may need significant additional material and can increase installation costs. Apart from this, the variability of PV outputs would make it difficult for the traditional "static" mitigation techniques to balance the combined effect of load and PV unbalance because the mitigation actions will not change with the variations of PV output. A new mitigation strategy is therefore necessary which can provide a dynamic balancing effect under the variably power unbalance produced by solar PV units and load demands. A method for voltage unbalance mitigation using energy storage has been proposed in [18]. In a previous work [2], the authors have explored the application of distributed energy storage devices integrated with rooftop PV systems for the mitigation of neutral current and NGV problems. But this strategy will use the storage devices installed at the customer premises. Therefore, the issues related to solving a utility concern by using customer installed storage devices need to be resolved through mutual agreement. Even if the storage devices are installed by the utility, access and maintenance would be another issue.

The concept of Community Energy Storage (CES) system [19] is becoming popular among the utilities [20-23]. It entails utility deployment of modular energy storage systems where one CES system is connected with multiple customers in a feeder to serve as a back-up power source, and also for different ancillary support including the buffering of customers' PV/wind energy and time shifting of energy for PEV charging [20]. With an appropriate control strategy, the CES system can also be used for mitigating neutral current and neutral voltage rise problems.

This paper proposes the application of CES systems for the mitigation of neutral voltage rise in LV distribution networks under an unbalanced allocation of 1-phase PV resources. The main contributions of this paper are to develop an algorithm to minimize the power consumption/delivery by the CES while mitigating the neutral current and NGV rise problems, and to develop a charging/discharging strategy using the proposed power balancing algorithm to provide a controllable mitigation effect under variable load and PV unbalance. This paper also develops a dynamic control model of the CES system combined with the distributed PV systems in the feeder to investigate the performance of the proposed mitigation approach in a dynamic environment with physical device time lags. The proposed approach is tested for its effectiveness in mitigating the neutral current and neutral voltage rise problems in the context of Australian LV distribution systems.

\section{LIMITATIONS OF TRADITIONAL TECHNIQUES FOR} MitigATION OF NEUTRAL VOLTAGE RISE FOR PV APPLICATION

Neutral current is produced by load and PV unbalance in a three phase 4-wire multigrounded LV feeder. A typical LV feeder with a number of households containing solar PV shown in Fig. 1 is used to demonstrate this.

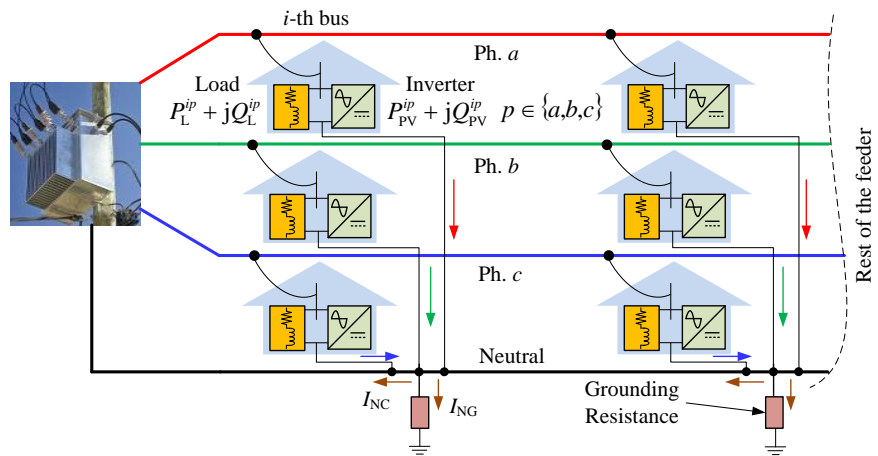

Fig. 1. Neutral current in a 4-wire multigrounded LV feeder produced by unbalanced load and PV allocation.

The total neutral current $I_{\mathrm{N}}$ produced by the power unbalance at any given $i$-th bus is divided into two parts: current flowing through the neutral grounding resistance $I_{\mathrm{NG}}$ and the current flowing through the neutral conductor $I_{\mathrm{NC}}$, as given in the expression below.

$$
\begin{gathered}
I_{\mathrm{N}}=I_{\mathrm{NG}}+I_{\mathrm{NC}}=-\sum_{p \in\{a, b, c\}}\left\{\frac{\left(P_{\mathrm{L}}^{i p}+\mathrm{j} Q_{\mathrm{L}}^{i p}\right)-\left(P_{\mathrm{PV}}^{i p}+\mathrm{j} Q_{\mathrm{PV}}^{i p}\right)}{\left(V_{\mathrm{re}}^{i p}+\mathrm{j} V_{\mathrm{im}}^{i p}\right)-\left(V_{\mathrm{re}}^{i n}+\mathrm{j} V_{\mathrm{im}}^{i n}\right)}\right\}^{*} \\
P_{\mathrm{L}}^{i a} \neq P_{\mathrm{L}}^{i b} \neq P_{\mathrm{L}}^{i c}, Q_{\mathrm{L}}^{i a} \neq Q_{\mathrm{L}}^{i b} \neq Q_{\mathrm{L}}^{i c} \\
P_{\mathrm{PV}}^{i a} \neq P_{\mathrm{PV}}^{i b} \neq P_{\mathrm{PV}}^{i c}, Q_{\mathrm{PV}}^{i a} \neq Q_{\mathrm{PV}}^{i b} \neq Q_{\mathrm{PV}}^{i c}
\end{gathered}
$$

where, * represents complex conjugate, $P_{\mathrm{L}}^{i p}, P_{\mathrm{PV}}^{i p}$ are the active power of the load and PV inverter at the $i$-th bus and $p$-th phase; $Q_{\mathrm{L}}^{i p}, Q_{\mathrm{PV}}^{i p}$ are the reactive power of the reactive power of the load and the PV inverter at the at the $i$-th bus and $p$-th phase; $V_{\mathrm{re}}^{i p}, V_{\mathrm{im}}^{i p}$ are the real and imaginary components of the phase voltage at the $i$-th bus; $V_{\mathrm{re}}^{\text {in }}, V_{\mathrm{im}}^{\text {in }}$ are the real and imaginary components of the neutral voltage at the $i$-th bus. If the PV inverters operate at unity power factor, $Q_{\mathrm{PV}}^{i p}$ will be zero.

Several methods for mitigation of neutral current and neutral voltage related issues have been reported in the literature. The traditional techniques for mitigation of neutral current and neutral voltage rise can be categorized into four groups [6]: (a) by mitigation of the conditions that cause or worsen NGV, e.g., load balancing, re-sizing of conductors, improvement of neutral grounding etc.; (b) by nullifying the current that produces $\mathrm{NGV}$; (c) by gradient control using 
equipotential planes; and (d) by electrical isolation. A typical 4-wire multigrounded Australian LV feeder is used to investigate the effectiveness of some common traditional mitigation strategies.

To create a load unbalance in the test feeder, phase $a$ and phase $c$ loads of the feeder are assumed to be $15 \%$ higher and $6 \%$ lower than phase $b$ loads, respectively. To create a higher level of PV unbalance as compared to load unbalance, the sizes of the PV units in phase $a$ and phase $c$ are assumed to be around $25 \%$ higher and $10 \%$ lower, respectively, than the PV units in phase $b$. To analyze the impact of the increase in the neutral grounding resistances, a value of $10 \mathrm{ohm}$ is used for all grounding resistances, based on the discussion presented in [9]. Fig. 2 shows the results of applying the traditional mitigation strategies that presents five typical NGV profiles identified by letters (A) to (E). Profile (A), corresponding to NGV value without rooftop PV, shows that the value of NGV during midday is around $0.8 \mathrm{~V}$ due to the light load demand and in the evening around $1.2 \mathrm{~V}$ due to the heavy load demand. Profile (B) corresponds to the NGV value with rooftop PV, but without any mitigation strategy, where the value of NGV during midday exceeds $1.7 \mathrm{~V}$. Profiles (C) to (E) correspond to the simulation results of the traditional mitigation strategies as described below.

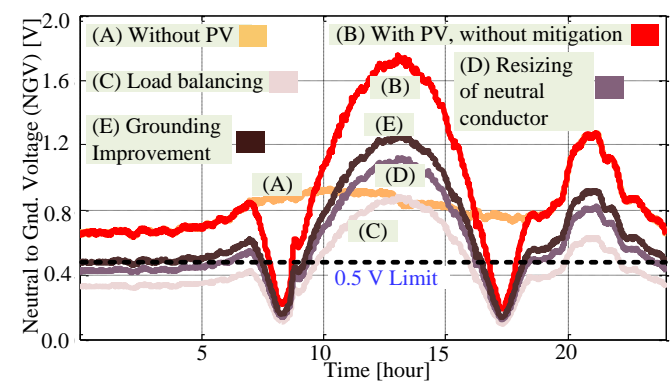

Fig. 2. NGV profiles with different traditional mitigation strategies.

\section{A. Load Balancing}

According to this strategy, loads are allocated in such a manner that an equal distribution of loads at each of the phases can be achieved [14, 15, 17]. As a result, neutral current and neutral voltage is reduced. In the presence of rooftop PV units, the load balancing will involve a combined balancing of load and PV systems. Mathematically, this can be described as a situation as given below.

$$
\begin{gathered}
\left(P_{\mathrm{L}}^{a}-P_{\mathrm{PV}}^{a}\right)=\left(P_{\mathrm{L}}^{b}-P_{\mathrm{PV}}^{b}\right)=\left(P_{\mathrm{L}}^{c}-P_{\mathrm{PV}}^{c}\right) \\
\left(Q_{\mathrm{L}}^{a}-Q_{\mathrm{PV}}^{a}\right)=\left(Q_{\mathrm{L}}^{b}-Q_{\mathrm{PV}}^{b}\right)=\left(Q_{\mathrm{L}}^{c}-Q_{\mathrm{PV}}^{c}\right)
\end{gathered}
$$

It is apparent that practically it is impossible to perform a perfect re-distribution of load and PV units to achieve a situation indicated in (2). Also, the load balancing by connection modification is a static type of solution which would not be effective in the presence of variable PV, and also due to a high growth rate of PV penetration. This will change the network condition for which load balancing was performed by reconfiguring the customer connections.

Considering the physical limitations of load balancing, it is assumed that the rearrangement of load and PV reduces the previous unbalances by $50 \%$. The value of NGV with such rearrangement reduces to $0.8 \mathrm{~V}$ approximately during midday and to $0.6 \mathrm{~V}$ approximately in the evening, as shown in profile (C). During midday, the value of NGV with load balancing is still above the limit.

\section{B. Re-sizing of Neutral Conductor}

Depending on the current path impedance, the neutral current flow is divided into two parts: one flows through the neutral conductor and the other flows through the neutral grounding resistance. If the neutral conductor is re-sized to have a lower impedance, the current flow through the neutral conductor will be increased and less current will flow through the grounding resistance. Therefore, the level of NGV will be reduced [14]. However, a resizing of the neutral conductor will involve additional material and construction cost. Also, the rating of the new neutral conductor selected based on a given PV penetration scenario may become inadequate before the expected planning period due to a high growth rate of PV penetration. The neutral wire impedance in the test feeder is reduced by $50 \%$ by increasing its size. As a result, the NGV value is reduced to $1.0 \mathrm{~V}$ during midday and $0.8 \mathrm{~V}$ in the evening, as shown in profile (D). Therefore, during the PV peak generation period, the value of $\mathrm{NGV}$ is still over the limit.

\section{Improvement of Grounding System}

This method aims to reduce the impedances of the grounding system so that the level of NGV is reduced for the same current flow [14]. Improvement of grounding system would be highly capital intensive, as it would incur additional grounding materials and construction costs over multiple locations in a distribution feeder. The neutral grounding resistance at each node of the test feeder is reduced to a typical value of $1.0 \mathrm{ohm}$. Even with such a reduced value, the NGV is found to be higher than $1.2 \mathrm{~V}$ during midday and higher than $0.8 \mathrm{~V}$ during the evening peak, as shown in profile (E).

\section{Isolation Transformer}

In this method, a separate transformer is used to isolate the source and load side, by not bonding the primary and secondary side neutrals, so that the primary side NGV cannot be propagated into the secondary side [13, 14, 16, 17]. However, this may cause an adverse effect on the protection of the load side of the transformer following lightning strike, system fault or wiring error [14]. The PV system producing a variable current over the day may increase the complexity of the new protection system design. Therefore, a trade-off analysis between the merits and demerits of isolation transformer method needs to be performed prior to implementation.

\section{E. Equipotential Planes}

In this method, a conductive wire mesh is installed over the area where the NGV problems appear and most of the conductive materials in that area are bonded with the mesh, to produce a level surface having the same electrical potential throughout, such that no potential difference exists on the surface $[13,14,16]$. Though this method does not mitigate the original cause of the neutral current and voltage problems, as 
long as one is on the surface, the potential of danger is removed [13, 14]. To achieve the benefits of the equipotential plane, a proper installation of the plane is essential, which involves additional grounding materials, wire mesh and new construction costs. For a high PV penetration, each of the households in the feeder will have to install this wire mesh which would not be feasible to implement.

\section{F. Active Voltage Suppression by Current Nullifying Device}

In this method, an active device is used to inject a current at some point in the neutral grounding system and the current is adjusted to cancel out the NGV [13]. Although this method has a certain level of controllability, its functionality depends on the resistance of a remote electrode system [13] which is "static". The current injection device consumes power from the distribution system. It also has the disadvantages of maintenance difficulty and high initial cost. Moreover, due to a high growth rate of PV penetration, control limits and ratings of the active suppression device may need to be changed more frequently than expected, which would increase the cost.

In the context of the limitations associated to the traditional mitigation strategies in the presence of a high penetration of single phase PV units, a new dynamic mitigation strategy using Community Energy Storage is proposed below.

\section{Proposed Community Energy Storage Based DYNAMIC MITIGATION STRATEGY}

One of the most noteworthy storage applications being tested across the U.S. [22] and in other countries [21] is extending storage to the edge of utility grids at the street level. This concept has been named as Community Energy Storage (CES), since the targeted loads are several residents on a distribution feeder supplied from a single utility distribution transformer (an example of which is shown in Fig. 3).

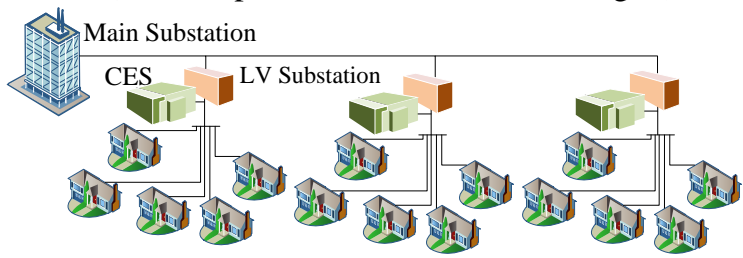

Fig. 3. A CES system serves multiple customers on an LV feeder.

Detroit Edison Energy (DTE) launched a project in 2012 to install $20 \times 50 \mathrm{kWh}$ CES systems in their service territory for peak shaving, demand response, voltage support, emergency load relief, integration of renewable generation and islanding during outages [22]. American Electric Power started one of the largest community energy storage projects in 2011 with a target of $80 \times 25 \mathrm{kWh}$ lithium ion battery packs next to distribution transformers to provide peak shaving, solar and wind variability smoothing and other ancillary support [23]. Scottish and Southern Energy in the UK is in the process of installing a few community energy storage systems [21]. A typical layout of the CES system being deployed by utilities is shown in Fig. 4. The CES system in Fig. 4 is connected to the individual customers using both $\mathrm{AC}$ and DC link [23] with appropriate metering arrangements to implement the necessary back-up support or ancillary service scheme. According to the functional specification of the CES system developed by
American Electric Power's Dolan Technology Center [24], the DC input modules of a CES system shall provide optional DC input modules to connect small wind and solar generating units. The voltage rating of the DC link will have to be determined based on the DC side voltage of the PV systems and the CES system, and the power rating will have to be determined using the peak DC power that needs to be handled.

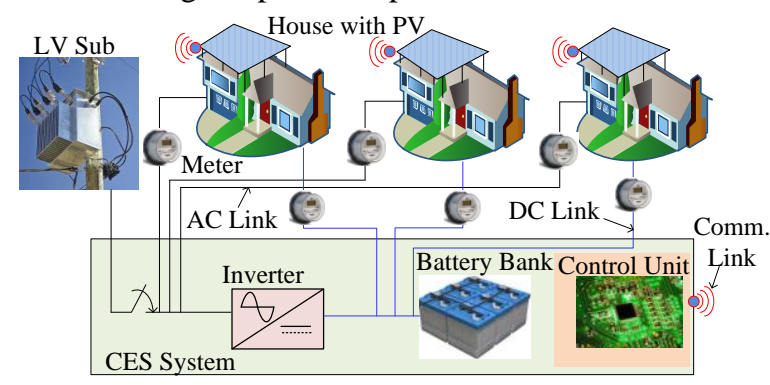

Fig. 4. Typical layout of a CES system connection with customers.

In this paper, the CES system is proposed for mitigation of neutral current and NGV by controlling the charging/discharging dynamically in such a way that it can continuously provide an appropriate power balancing effect. For this case, the power connection between the CES and each of the PV systems will be through a common DC bus connected to the bi-directional DC/DC converter of the PV system, as shown in Fig. 5.

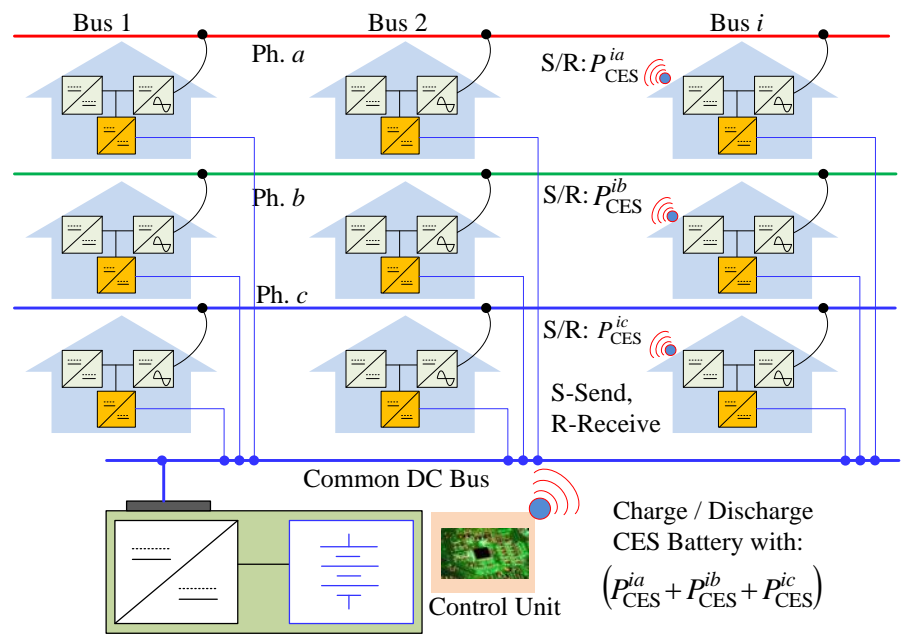

Fig. 5. Schematic diagram of the proposed CES system based strategy.

With the prospect of smart DC micro-grid technologies [25, 26], such common DC link would become available. The CES control system will collect measurement signals such as load, PV generation etc. from all of the PV connection points and will determine the amount of power to be absorbed/delivered by the CES system from/to each of the PV systems.

In principle, the power to be consumed or generated by the CES battery at any given time instant is equal to the total power that needs to be consumed from or delivered to the whole feeder for balancing operation. The total power is obtained by summing up the power at the individual households. Using a power balancing algorithm (described later), the control system determines the power to be consumed from or delivered to the individual households. Then commands are issued to the bi-directional DC/DC converters of the PV systems at phase $a, b$ and $c$ to send/ 
receive power $P_{\mathrm{CES}}^{i a}, P_{\mathrm{CES}}^{i b}, P_{\mathrm{CES}}^{i c}$, respectively, to/ from, the CES system. At the same time, a command is issued to the CES system to charge/discharge the CES battery with a power equal to $\left(P_{\mathrm{CES}}^{i a}+P_{\mathrm{CES}}^{i b}+P_{\mathrm{CES}}^{i c}\right)$. For illustration, it is assumed that the values of $P_{\text {grid }}$ at phase $a, b$ and $c$ at the $i$-th bus is $-3,-2,-1$ $\mathrm{kW}$ respectively (-ve indicates reverse power flow). Using the values of $P_{\text {grid }}$, the power balancing algorithm (which is described later in the next subsection) determines that the values of $P_{\mathrm{CES}}^{i a}, P_{\mathrm{CES}}^{i b}, P_{\mathrm{CES}}^{i c}$ will be 2,1 , and $0 \mathrm{~kW}$ respectively. Commands are then sent to the respective PV systems at the $i$ th bus to send the appropriate amount of power. At the same time, a command is sent to charge the CES battery with $(2+1+0)=3 \mathrm{~kW}$ of power. Again, if the values of $P_{\text {grid }}$ at phase $a, b$ and $c$ at the $i$-th bus is $3,2,1 \mathrm{~kW}$ respectively (+ve indicates forward power flow), then commands are sent to the PV system to receive 2,1 , and $0 \mathrm{~kW}$ of power from the CES system and the same time command is sent to discharge the battery with $3 \mathrm{~kW}$ of power.

As understood from the example, in addition to the communication links, this strategy will also need a certain level of control access to operate the customer PV systems to send/receive power to/from the CES battery. With an advanced level deployment of smart grid technologies and with arrangements between the customers and the utility, this type of strategy can be adopted in new or future distribution grids.

\section{A. Development of a Dynamic Power Balancing Algorithm}

The amount of power to be consumed or delivered at each of the phases of a given $i$-th bus for balancing operation at $k$-th time instant can be obtained as given below.

$$
\begin{aligned}
& P_{\mathrm{CES}}^{i p}(k)=P_{\text {grid }}^{\text {ref } i}(k)-P_{\text {grid }}^{i p}(k) \\
& P_{\text {grid }}^{i p}(k)=P_{\mathrm{L}}^{i p}(k)+P_{\mathrm{B}}^{i p}(k)-P_{\mathrm{PV}}^{i p}(k) \\
& p \in\{a, b, c,\}
\end{aligned}
$$

In (3), $P_{\text {grid }}^{\text {ref } i}$ is the reference power exchange for bus $i$, $P_{\mathrm{CES}}^{i p}$ is the power to be absorbed from or delivered to the PV system by the CES system, $P_{\text {grid }}^{i p}$ is the power exchange with grid, $P_{\mathrm{B}}^{i p}$ is the power consumed or delivered by the local energy storage device (if any), all for the respective phases.

The value of $P_{\text {grid }}^{\text {ref } i}(k)$ that will result in the minimum power consumption or delivery by the CES system at the $k$-th instant can be obtained from a constrained minimization problem, as given below.

$$
\begin{gathered}
\text { minimize: }\left\{\sum_{i=1}^{m} \sum_{p \in\{a, b, c\}} P_{\mathrm{CES}}^{i p}(k)\right\} \text {, subject to: } \\
{\left[\begin{array}{c}
\mathbf{0} \\
\mathbf{0} \\
\vdots \\
\mathbf{0}
\end{array}\right]=-\left[\begin{array}{cccc}
\mathbf{A}_{\mathrm{CES}}^{1} & \mathbf{0} & \cdots & \mathbf{0} \\
\mathbf{0} & \mathbf{A}_{\mathrm{CES}}^{2} & \cdots & \mathbf{0} \\
\vdots & \vdots & \ddots & \vdots \\
\mathbf{0} & \mathbf{0} & \cdots & \mathbf{A}_{\mathrm{CES}}^{m}
\end{array}\right]\left[\begin{array}{c}
\mathbf{P}_{\mathrm{CES}}^{1}(k) \\
\mathbf{P}_{\mathrm{CES}}^{2}(k) \\
\vdots \\
\mathbf{P}_{\mathrm{CES}}^{m}(k)
\end{array}\right]+\left[\begin{array}{c}
\mathbf{P}_{\text {grid }}^{1}(k) \\
\mathbf{P}_{\text {grid }}^{2}(k) \\
\vdots \\
\mathbf{P}_{\text {grid }}^{m}(k)
\end{array}\right]}
\end{gathered}
$$

$$
\begin{aligned}
& P_{\mathrm{CES}}^{i a}(k) \times P_{\mathrm{CES}}^{i b}(k) \geq 0 \\
& P_{\mathrm{CES}}^{i b}(k) \times P_{\mathrm{CES}}^{i c}(k) \geq 0 \\
& P_{\mathrm{CES}}^{i c}(k) \times P_{\mathrm{CES}}^{i a}(k) \geq 0
\end{aligned}
$$

where,

$$
\begin{aligned}
& \mathbf{A}_{\mathrm{CES}}^{i}=\left[\begin{array}{ccc}
0 & -1 & 0 \\
0 & 1 & -1 \\
-1 & 0 & 1
\end{array}\right], \mathbf{P}_{\mathrm{CES}}^{i}(k)=\left[\begin{array}{lll}
P_{\mathrm{CES}}^{i a}(k) & P_{\mathrm{CES}}^{i b}(k) & P_{\mathrm{CES}}^{i c}(k)
\end{array}\right]^{T}
\end{aligned}
$$

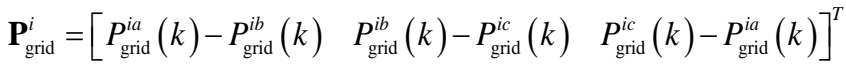

$$
\begin{aligned}
& i=1,2, \cdots m
\end{aligned}
$$

The equation in 4(a) is the objective function of the optimization problem which is formulated by summing up the power corresponding to all the households in the feeder that is to be stored or delivered by the CES system. Minimizing this power at each instant of time ensures that the capacity usage in a given interval of time is the minimum, and hence it can lead to the reduction of the size of the CES battery. A lower size of the battery means a lower initial cost, and also a lower operating cost and maintenance complexity. Further, the CES is a limited energy system, and hence it is important that the energy is not used up too early during discharging, or to be too quickly fully charged when charging. Equation 4(b) is a set of linear constraints that enforces the condition that the net power exchange with the grid, that is, the difference between $P_{\text {grid }}^{i p}$ and $P_{\mathrm{CES}}^{i p}$ at all the phases in a bus are equal; this is the main objective of power balancing. Equation 4(c) is a set of nonlinear constraints that is used to specify that either discharging or charging operation will be used because it is not practically possible to charge and discharge the same CES battery at a given instant of time. This is done by forcing the signs of $P_{\mathrm{CES}}^{i p}$ at all the phases to be the same.

Examining the solutions of (4) it is found that if all the values of $P_{\text {grid }}^{i p}(k)$ have same signs (either +ve or -ve), the values of $P_{\text {grid }}^{\text {ref }-i}(k)$ can be obtained as given below in (5).

$$
P_{\text {grid }}^{\text {ref }-i}(k)=\min \left\{\left|P_{\text {grid }}^{i a}(k)\right|,\left|P_{\text {grid }}^{i b}(k)\right|,\left|P_{\text {grid }}^{i c}(k)\right|\right\}
$$

Using (5) will enable avoiding the computational burden of solving (4) for the cases when all the values of $P_{\text {grid }}^{i p}(k)$ have same signs. It is apparent from (3)-(5) that the appropriate amount of power to be consumed or generated by the CES system for a given phase at a given bus is determined using the load and PV generation at the different phases of that given bus only. The total power for the CES system is then determined by summing up the individual values. Extending the system size by adding more buses or increasing the load and PV size does not require any modification of the algorithm itself. Therefore, the algorithm is fully scalable with respect to the system size. However, in the actual implementation, the CES battery has to be sized properly with respect to the system size. 


\section{B. Charging/Discharging Control of the CES System}

At a given time instant $k$, with the total amount of power to be consumed or delivered by the CES system dedicated for the whole feeder, the charging/discharging rate (battery current) of the CES battery can be obtained using the expression below.

$$
I_{\mathrm{CES}}(k)=\frac{\sum_{i=1}^{m} \sum_{p \in\{a, b, c\}} P_{\mathrm{CES}}^{i p}(k)}{V_{\mathrm{CES}}(k)}=\frac{\sum_{i=1}^{m} \sum_{p \in\{a, b, c\}} P_{\mathrm{CES}}^{i p}(k)}{f\left\{\operatorname{SoC}(k), C_{\mathrm{CES}}, \mathbf{p}\right\}}
$$

where, $I_{\mathrm{CES}}$ is the charging/discharging rate of the CES, $V_{\mathrm{CES}}$ is the CES voltage which is a function of the battery SoC, $C_{\mathrm{CES}}$ is the capacity of the CES battery, and $\mathbf{p}$ is a set of battery modeling parameters. The control strategy for the charging/discharging of the CES system for the balancing operation is shown in Fig. 6.

The values of $P_{\text {grid }}(k)$ at all the buses are collected through the communication link. If the values of $P_{\text {grid }}(k)$ at all of the households are negative (indicating a reverse power flow), then balancing is performed by a charging operation. On the other hand, if the values of $P_{\text {grid }}(k)$ at all of the households are positive (indicating a forward power flow), then balancing is performed by a discharging operation. However, if the values of $P_{\text {grid }}(k)$ have both positive and negative sign, (4) is solved for both charging and discharging operation and the option producing the minimum value of the total power obtained from 4(a), is finally used. Once the appropriate option (charging/discharging) is selected, the amount of power to be received from or sent to each of the households by the CES system is determined either using (3), when the signs of $P_{\text {grid }}(k)$ at all the households are same; or, using the solution of (4), when $P_{\text {grid }}(k)$ has positive and negative values. The amounts of power determined are then communicated to the PV inverter system at each of the households. At the same time, the charging or discharging operation is performed using the rates determined by (6), and with the necessary checks of the SoC limits. The CES battery is allowed to be charged if the current $\mathrm{SoC}$ is less than $\mathrm{SoC}_{\max }$ to avoid overcharging. Similarly, the battery is allowed to be discharged if the current SoC is higher than $\mathrm{DoD}_{\max }$ to avoid discharging over the limit.

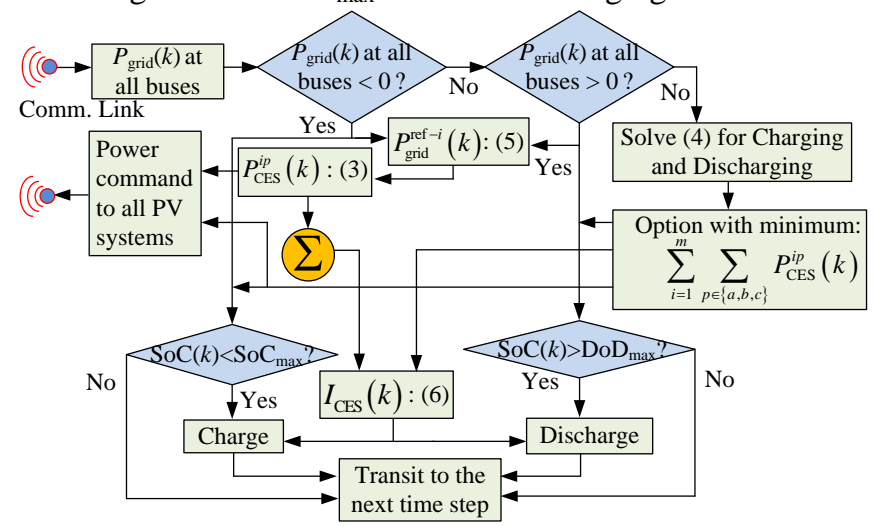

Fig. 6. The dynamic balancing control strategy with CES.

\section{Dynamic Control Model of the CES System}

Power electronic systems in the PV inverters and in the CES system will have physical time lags. To investigate how the proposed mitigation approach performs under such time delays, especially in the presence of sudden changes in PV outputs caused by cloud passing, a dynamic model of the integrated system consisting of the CES and the PV inverters is developed. The DC/DC and inverter blocks, and the CES battery are represented by first order delays, as shown in Fig. 7.

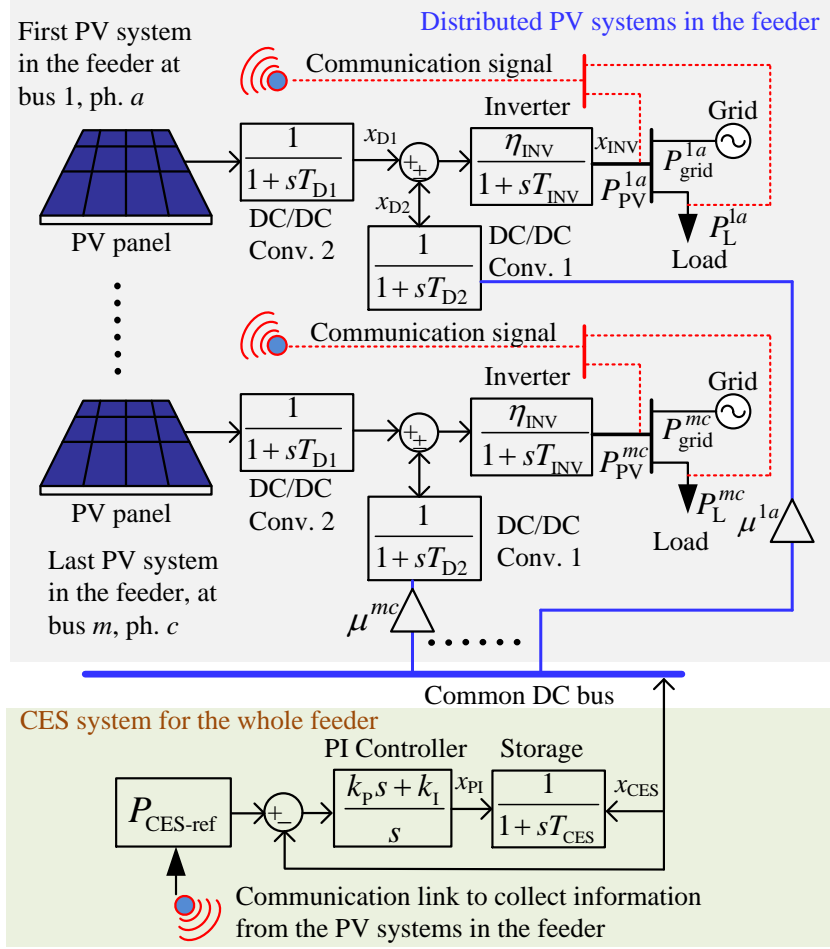

Fig. 7. Dynamic control model of the CES system integrated with distributed PV systems in the feeder.

The state equations corresponding to the PI controller output $x_{\mathrm{PI}}$ and the CES output $x_{\mathrm{CES}}$ are given below.

$$
\begin{gathered}
\frac{d x_{\mathrm{PI}}}{d t}=-\frac{1}{T_{\mathrm{CES}}}\left(x_{\mathrm{PI}}-x_{\mathrm{CES}}\right) k_{\mathrm{P}}+\left(P_{\mathrm{CES}-\text { ref }}-x_{\mathrm{CES}}\right) k_{\mathrm{I}} \\
\text { where, } P_{\mathrm{CES}-\text { ref }}=\sum_{i=1}^{m} \sum_{p \in\{a, b, c\}} P_{\mathrm{CES}}^{i p} \\
\frac{d x_{\mathrm{CES}}}{d t}=\frac{1}{T_{\mathrm{CES}}}\left(x_{\mathrm{PI}}-x_{\mathrm{CES}}\right)
\end{gathered}
$$

where, $T_{\mathrm{CES}}$ is the time constant of the CES, $P_{\mathrm{CES} \text {-ref }}$ is the set point, and $k_{\mathrm{P}}, k_{\mathrm{I}}$ are the proportional and integral gains of the PI controller.

The CES battery output is distributed among all the customers connected to the feeder using a distribution factor $\mu$, which can be obtained for a given household at the $i$-th bus and $p$-th phase using the expression below.

$$
\mu^{i p}=\frac{P_{\mathrm{CES}}^{i p}}{\sum_{i=1}^{m} \sum_{p\{a, b, c\}} P_{\mathrm{CES}}^{i p}}
$$

The differential equations corresponding to the DC/DC converter outputs $\left(x_{\mathrm{D} 1}, x_{\mathrm{D} 2}\right)$ and the inverter output $\left(x_{\mathrm{INV}}\right)$ in a PV system at the $i$-th bus and $p$-th phase are given below.

$$
\frac{d x_{\mathrm{D} 1}^{i p}}{d t}=\frac{1}{T_{\mathrm{D} 1}^{i p}}\left(P_{\mathrm{DC}}^{i p}-x_{\mathrm{D} 1}^{i p}\right)
$$




$$
\begin{gathered}
\frac{d x_{\mathrm{D} 2}^{i p}}{d t}=\frac{1}{T_{\mathrm{D} 2}^{i p}}\left(\mu^{i p} \times x_{\mathrm{CES}}-x_{\mathrm{D} 2}^{i p}\right) \\
\frac{d x_{\mathrm{INV}}^{i p}}{d t}=\frac{1}{T_{\mathrm{INV}}^{i p}}\left(\eta_{\mathrm{INV}}^{i p} x_{\mathrm{D} 1}^{i p} \pm \eta_{\mathrm{INV}}^{i p} x_{\mathrm{D} 2}^{i p}-x_{\mathrm{INV}}^{i p}\right)
\end{gathered}
$$

where, $P_{\mathrm{DC}}$ is $\mathrm{PV}$ panel DC power, $T_{\mathrm{D} 1}$ and $T_{\mathrm{D} 1}$ are the time constants of the DC/DC converters and $T_{\mathrm{INV}}$ is the time constant of the inverter.

The PI controller of the CES system is tuned to have a low rise time so that the low response time of modern storage devices can be effectively utilized for the mitigation of neutral current and NGV problems, especially during cloud passing transients. The controller parameters, shown in Appendix I, are obtained using an open-loop frequency response of the linearized plant model. The tuning task is performed with the aid of Simulink Automatic PID tuner [27] that performs the tuning task based on a reference tracking algorithm while maintaining the closed loop stability, and a trade-off between performance and robustness.

\section{APPLICATION EXAMPLES}

A typical 0.4-kV Australian LV distribution feeder with 30 households (HHs), as shown in Fig. 8, is used for the verification of the proposed strategy. The $\mathrm{R} / \mathrm{X}$ ratio of the feeder is 3.0 which reflect the highly resistive nature of $\mathrm{LV}$ distribution circuits.

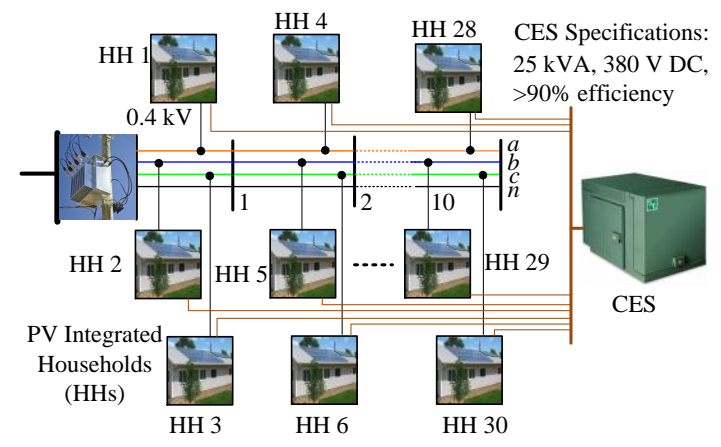

Fig. 8. Test LV feeder integrated with the CES system.

The unbalances in household loads and PV systems are set up similar to the scenario presented in Fig. 2 so that the performance of the proposed approach can be compared with the traditional approach. The solar PV data is obtained from the Renewable Energy Integration Facility at Commonwealth Scientific and Industrial Research Organisation (CSIRO) Energy Technology in Australia and the load data is derived from an Australian distribution utility. Depending on the total amount of surplus solar energy available from the whole feeder throughout the day, a $100 \mathrm{kWh}$ Li-Ion battery is considered for the simulation of the CES system.

Modeling and simulation of the test system is performed using a MATLAB based three-phase power flow analysis tool [28] developed by the authors which is capable to deal with low and medium voltage distribution networks with different wiring configurations, including solar PV and energy storage systems. Simulation time step is determined based on the resolution of the measured PV data.

The load demand and PV output profiles at the three phases are such that $P_{\text {grid }}$ profiles determined using (3) are of same sign (either positive or negative) for most of the 24 hours period, except for a few minutes in the morning and in the evening when the profiles have mixed signs as shown in Fig 9. This is due to the fact that when PV output varies with the progress of the day, different level of $P_{\text {grid }}$ can be created at different phases due to unbalanced load and PV generation.

When $P_{\text {grid }}$ at all the phases have the same sign, $P_{\text {grid }}^{\text {ref } i}$ is determined using (5). However, when $P_{\text {grid }}$ at different phases have different signs, $P_{\text {grid }}^{\text {ref } i}$ is deactivated (value is zero, as shown in Fig. 9), and (4) is used to determine the appropriate option for power balancing, which is in accordance with the control strategy given in Fig. 6. The optimization problem in (4) is solved using the MATLAB optimization toolbox available with MATLAB 7.10.0 (R2010a). The average computational time for the given network using an Intel Core i7 $2.93 \mathrm{GHz}$ CPU is approximately 35 milliseconds.
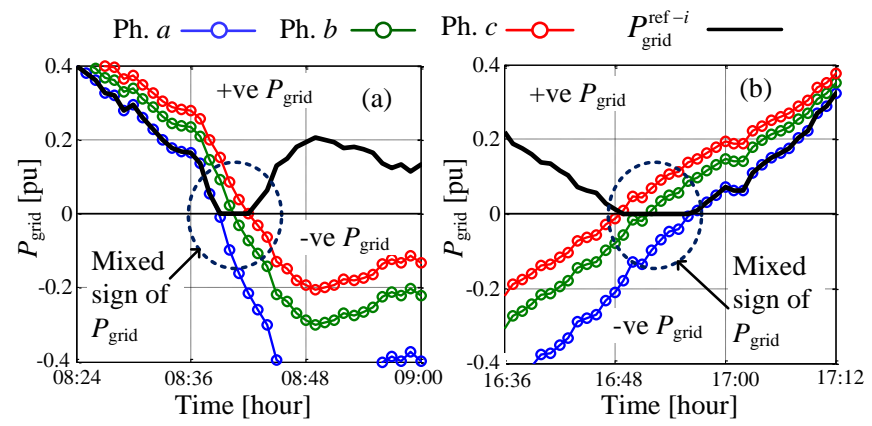

Fig. 9. The values of $P_{\text {grid }}$ at different phases. (a) Morning. (b) Evening.

The benefit of controlling the CES system using the charging or discharging rate obtained by (3)-(6) is evident from Fig. 10.

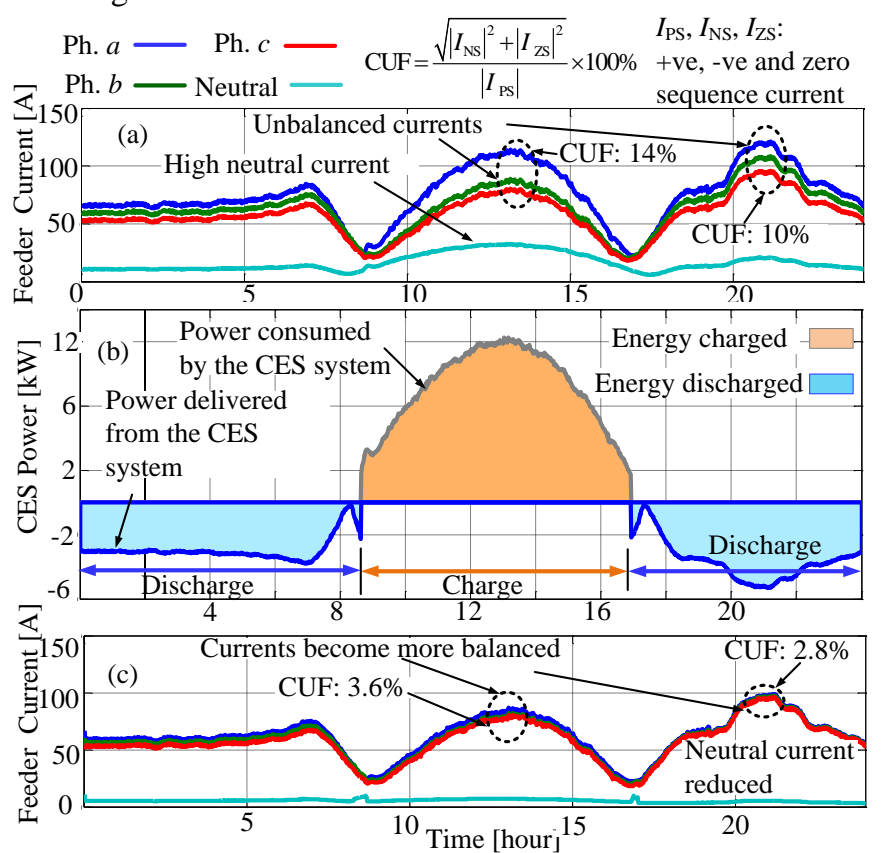

Fig. 10. Mitigation of neutral current using the proposed strategy. (a) Feeder current without CES. (b). CES power. (c). Feeder current with CES.

The total feeder current flowing from the LV substationend of the feeder is shown in Fig. 10(a). It is observed that with substantial amount unbalance created by the load demand and the PV generation, a significant level of neutral current is 
produced. This increase of neutral current is also associated with a high Current Unbalance Factor (CUF) [29] determined using the zero, negative and positive sequence components of the feeder current. In the midday during peak PV period, the value of CUF is $14 \%$, and during the evening peak load period, it is $10 \%$. To mitigate the neutral current, the CES system is operated according to the proposed control strategy. The total power stored from or delivered to the entire LV feeder by the CES system for balancing operation during a 24 hours period is shown in Fig. 10(b). During nighttime, the PV power is not available and therefore, balancing is performed by discharging operation as shown in Fig. 10(b). During daytime when PV power is available, balancing operation is performed by charging operation as shown in Fig. 10(b). The energy stored during charge operation and the energy delivered during the discharge operation is also shown in Fig. 10(b) using the shaded regions.

With the proposed balancing operation, the current unbalance is significantly reduced (to $3.6 \%$ in the midday and to $2.8 \%$ in the evening peak) using the proposed approach and therefore an appreciable mitigation of the neutral current is observed in Fig. 10(c).

The NGV profiles at the substation-end bus and at the remote-end bus of the LV feeder without balancing action are compared in Fig. 11 with the NGV profiles at the same buses obtained by the proposed balancing action. It is observed that with the power balancing operation, the NGV values are reduced significantly during midday PV peak and also during the evening peak load period. For reference, the NGV profiles at the other buses of the LV feeder have also been included in Fig. 11. It is found that the proposed mitigation strategy has reduced the NGV values all over the LV feeder below the limit of $0.5 \mathrm{~V}$.

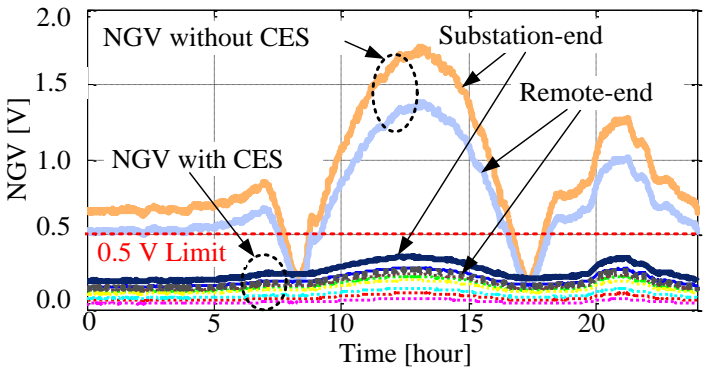

Fig. 11. NGV profiles at different buses of the LV feeder.

The mitigation of neutral current and NGV is more clearly shown in Fig. 12. With the application of the proposed CES based strategy, the neutral current is reduced by $80 \%$ during midday PV peak and by $71 \%$ during the evening peak, as shown in Fig. 12(a). As a result, the NGV is also reduced by nearly the same percentage, as shown in Fig. 12(b).

The analysis results presented above demonstrated the performance of the proposed dynamic mitigation strategy in a scenario where the PV output profile corresponds to a clear sunny day with no fluctuation in the PV output. Therefore, balancing is mainly performed by charging operation during the daytime and by discharging operation during the nighttime. In a partly cloudy day, however, there will be fluctuations in the PV output and balancing operation will be performed by both charging and discharging operation in daytime. To investigate the performance of the proposed strategy in a cloudy day, another long term simulation is performed using a PV generation profile captured by NREL [30] at 1 -second interval is used.
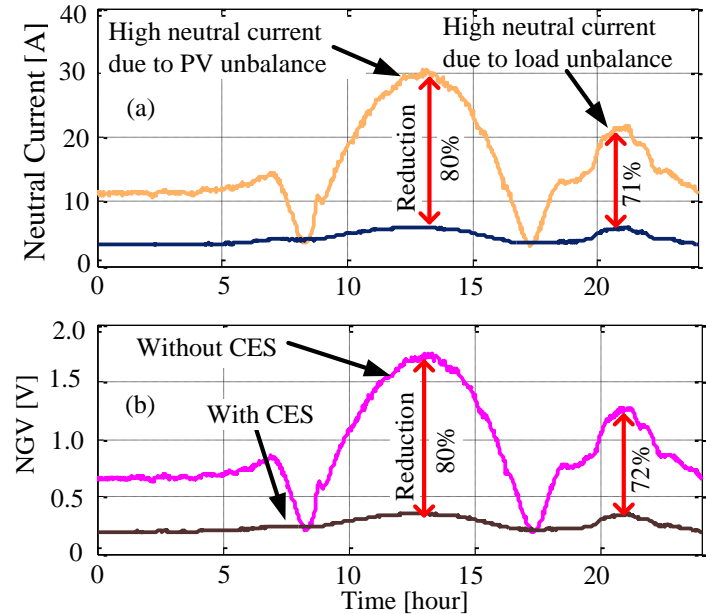

Fig. 12. Reduction in the neutral current and NGV with and without mitigation. (a) Neutral current (b) NGV.

At first, a quasi steady state analysis is performed using a 350 seconds segment of the PV output profile, where several fluctuations occurred and therefore both charging and discharging will be required for balancing operation. Fig. 13 shows the effect of the CES operation on $P_{\text {grid }}$ profiles corresponding to three phases at Bus 1 of the feeder in Fig. 8.

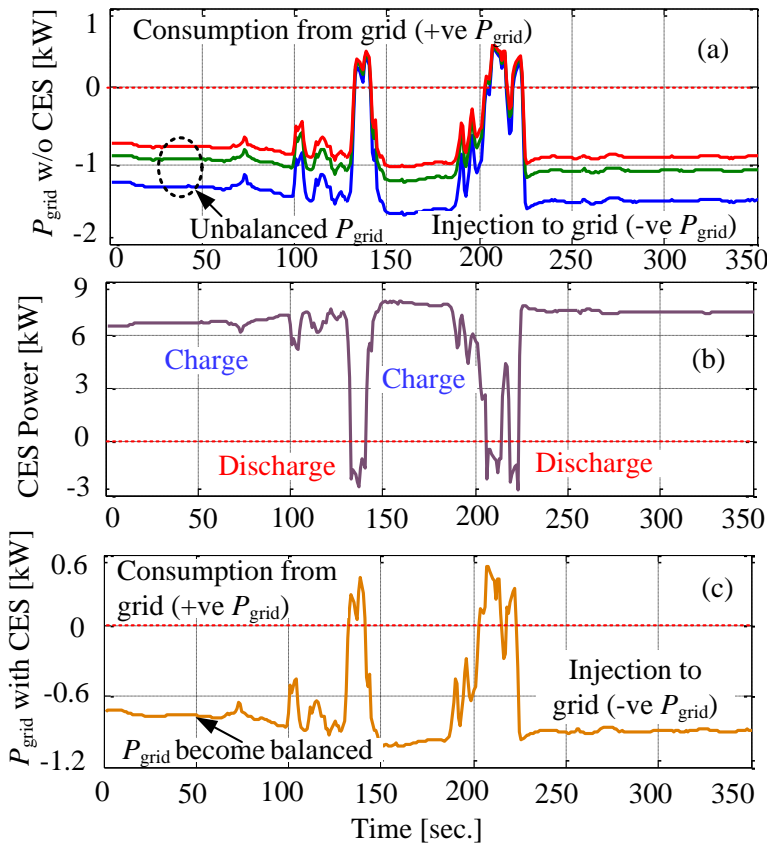

Fig. 13. Performance of the proposed approach under fluctuating PV output. (a) $P_{\text {grid }}$ without CES (b) CES power. (c) $P_{\text {grid }}$ with CES.

Unbalanced $P_{\text {grid }}$ profiles due to unbalanced PV power injection (during reverse power flow) and consumption (during low PV output caused by cloud passing) at the phases are shown in Fig. 13(a). Applying the proposed control strategy, the CES system is charged and discharged appropriately with the amount of power determined using (3)(5); the CES power profile is shown in Fig. 13(b). In effect, 
the $P_{\text {grid }}$ profiles at all phases become balanced, as observed in Fig. 13(c). As a result of the proposed balancing operation, the neutral current and hence the NGV is reduced, as shown in Fig. 14(a) and (b), respectively.
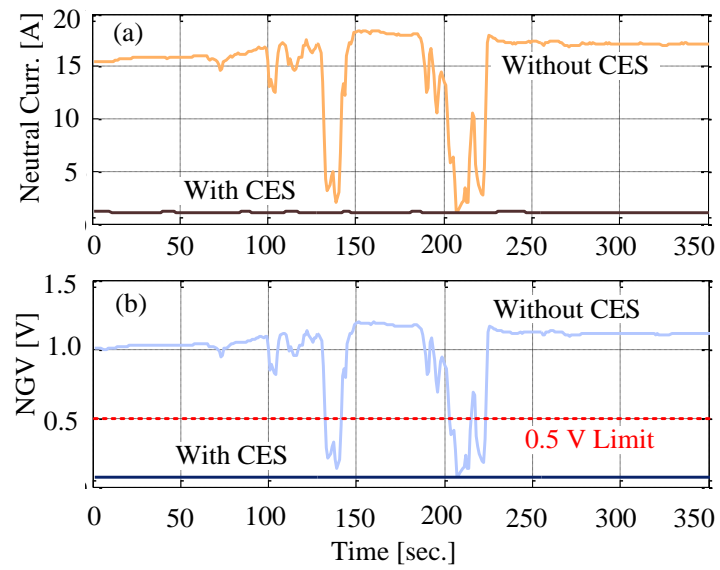

Fig. 14. Neutral current and NGV with and without CES during PV output fluctuation. (a) Neutral current mitigation. (b) NGV mitigation.

A 20 second segment of the PV output profile (200 to 220 second) used in Fig. 13 is taken for dynamic simulation of the proposed strategy; this segment includes several fluctuations that needs multiple charging-discharging transitions. The dynamic model developed in Fig. 7 is used for this simulation. Unbalanced $P_{\text {grid }}$ profiles at all the phases over the 20 seconds period are shown in Fig. 15(a). As seen in Fig. 15(b), with the proposed strategy, the CES power dynamically varies over this period to provide an appropriate balancing effect; the chargedischarge transitions are identified in Fig. 15(b). As a result of the CES control, the $P_{\text {grid }}$ profiles become balanced, as shown in Fig. 15(c), which in turn mitigates the neutral current and $\mathrm{NGV}$, as shown in the dynamic response of the neutral current and NGV presented in Fig. 16(a) and (b), respectively.

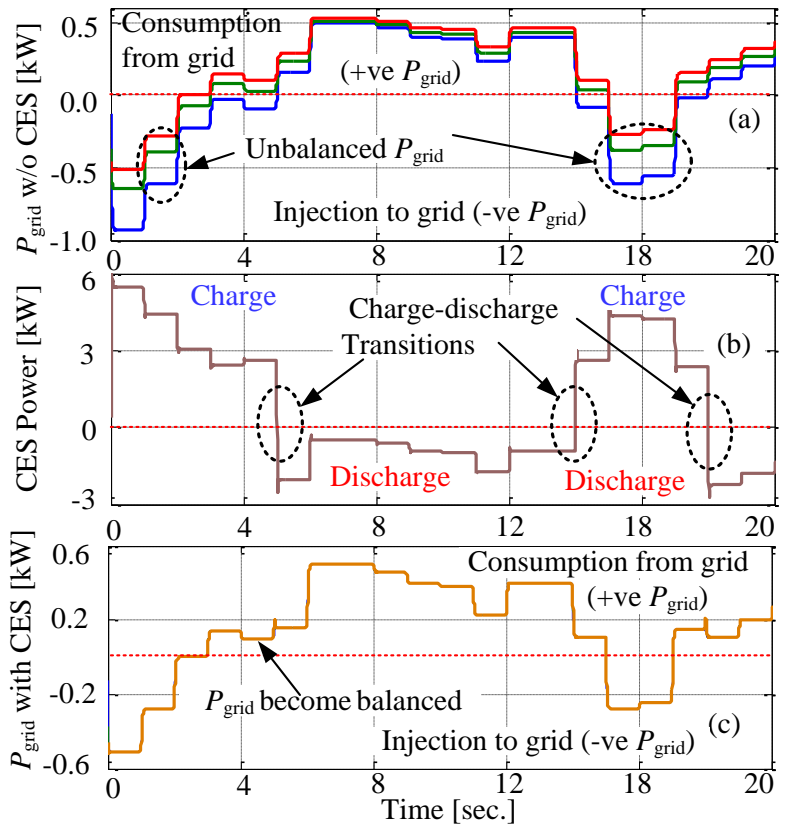

Fig. 15. Dynamic performance of the proposed approach under fluctuating PV output. (a) $P_{\text {grid }}$ without CES (b) CES power. (c) $P_{\text {grid }}$ with CES.

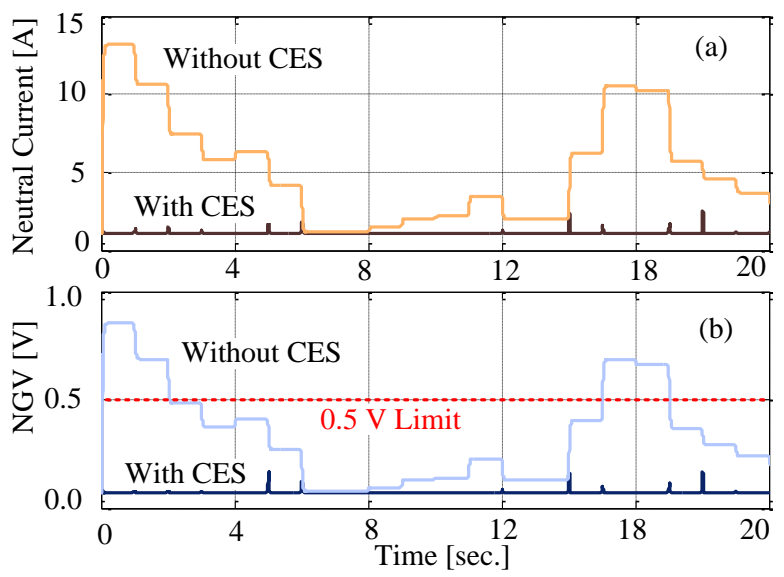

Fig. 16. Dynamic response of neutral current and NGV obtained using the dynamic model. (a) Neutral current. (b) NGV.

A segment of the CES power profile in Fig. 15(b) from 16.8 to 18.4 second is shown in Fig. 17(a) where the dynamic transition from the charging mode to discharging mode is observed more clearly. The resulting NGV profile in Fig. 17(b) shows the transient response of the NGV due to the charging-discharging transition. It is observed that with an appropriately tuned controller, the charge-discharge transitions would be smooth and the resulting transients would be small $(0.1 \mathrm{~V}$ overshoot in this case), and also will stabilize very fast.
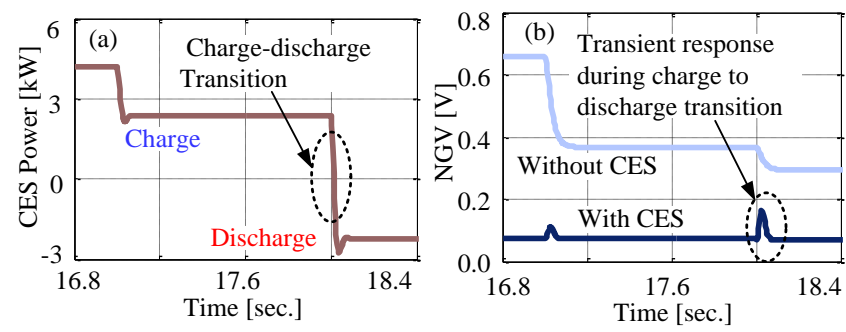

Fig. 17. Transient response during charge-discharge transition. (a) CES power. (b) NGV.

The proposed strategy mitigates of the neutral current and NGV problems by storing surplus energy during PV peak period and releasing the stored energy during the evening peak load. In addition to mitigating NGV problem, this operation brings the benefit of partially mitigating voltage rise impact of PV and also supports the voltage evening peak load helps thereby to maintain feeder voltage within acceptable limits, which is $-6 \%$ to $+10 \%$ of the nominal value for the Australian LV distribution systems.

\section{CONCLUSION}

This paper has proposed the application of Community Energy Storage (CES) for the dynamic mitigation of the neutral current and neutral voltage rise problems created by an unbalanced allocation of solar PV in 4-wire multigrounded LV networks. Investigations showed that the traditional mitigation strategies are not able to reduce the neutral voltage below the acceptable level, because these strategies do not directly act to mitigate the combined effect of load and PV unbalance, especially with the PV output variability and load changes at different phases in the LV networks. With this background, 
CES system has been proposed to dynamically balance the power exchange with the grid in all three phases so that the neutral current and NGV problems are reduced. A constrained minimization based power balancing algorithm has been developed to balance the net power exchange with the grid utilizing the minimum amount of CES power. A control strategy has been developed based on the balancing algorithm to control the CES system to provide an appropriate balancing effect under varying load and PV unbalance. Analysis performed using an Australian distribution feeder proves that the proposed strategy is able to reduce the neutral current, which results in the mitigation of the NGV problem. Analysis using a dynamic model of the integrated network with distributed PV systems and the central CES system shows that with a fast battery storage device and an appropriately tuned controller, a dynamic solution for continuous mitigation of the neutral current and NGV can be achieved.

\section{APPENDIX I}

DYNAMIC MODEL AND CONTROLLER PARAMETERS

\begin{tabular}{l|l}
\hline \hline \multicolumn{1}{c|}{ Parameter } & \multicolumn{1}{c}{ Value } \\
\hline \hline$T_{\mathrm{CES}}, T_{\mathrm{D} 1}, T_{\mathrm{D} 2}, T_{\mathrm{INV}}, \eta_{\mathrm{INV}}$ & $6 \mathrm{mS}, 6 \mathrm{mS}, 6 \mathrm{mS}, 12 \mathrm{mS}, 89.5 \%$ \\
\hline$K_{\mathrm{P}}, K_{\mathrm{I}}$ & $0.48,261.4$ \\
\hline \hline
\end{tabular}

\section{REFERENCES}

[1] J. C. Balda, A. R. Oliva, D. W. McNabb, and R. D. Richardson, "Measurements of neutral currents and voltages on a distribution feeder," IEEE Transactions on Power Delivery, vol. 12, pp. 1799-1804, 1997.

[2] M. J. E. Alam, K. Muttaqi, and D. Sutanto, "Effectiveness of Traditional Mitigation Strategies for Neutral Current and Voltage Problems under High Penetration of Rooftop PV," in IEEE PES General Meeting, Vancouver, British Columbia, Canada, Jul. 21 - 25, 2013.

[3] B. Mather. (Oct. 2012). High Penetration Projects in the US [Online]. Available: http://www.iea-pvps.org/

[4] M. Rekinger. (Nov. 2013). High PV penetration in the European context [Online]. Available: http://apvi.org.au/wpcontent/uploads/2013/12/Manoel-Rekinger-EPIA-High-PV-penetrationin-the-European-context.pdf

[5] A. Bruce. High PV Penetration in Electricity Grids [Online]. Available: http://www.ceem.unsw.edu.au/sites/default/files/event/documents/April20 12BruceHighPentrationAustCaseStudies.pdf

[6] G. Mokhtari, A. Ghosh, G. Nourbakhsh, and G. Ledwich, "Smart Robust Resources Control in LV Network to Deal With Voltage Rise Issue," IEEE Transactions on Sustainable Energy vol. 4, pp. 1043-1050, 2013.

[7] M. E. Baran, H. Hooshyar, S. Zhan, and A. Huang, "Accommodating High PV Penetration on Distribution Feeders," IEEE Transactions on Smart Grid, vol. 3, pp. 1039-1046, 2012.

[8] A. Hoke, R. Butler, J. Hambrick, and B. Kroposki, "Steady-State Analysis of Maximum Photovoltaic Penetration Levels on Typical Distribution Feeders," IEEE Transactions on Sustainable Energy, vol. 4, pp. 350-357, 2013.

[9] J. Werda, J. Chan, and P. Freeman. Electrical Earthing - Risk Management Strategies for the Water Industry, presented at the 2nd Annual Water Industry Engineers and Operators Conference, Newcastle, NSW, Australia, 8-10 April, 2008. [Online]. Available: http://www.wioa.org.au/conference_papers/08_nsw/documents/johnwerd a.pdf

[10]T. M. Gruzs, "A survey of neutral currents in three-phase computer power systems," IEEE Transactions on Industry Applications vol. 26, pp. 719$725,1990$.

[11]Power Quality - The Basics [Online]. Available: http://www.psihq.com/iread/pqbasics.htm

[12]D. W. Zipse, "The hazardous multigrounded neutral distribution system and dangerous stray currents," in IEEE Industry Applications Society 50th Annual Petroleum and Chemical Industry Conference, Houston, TX, USA, 15-17 Sep., 2003, pp. 23-45.

[13] Effects of Electrcal Voltage/Current on Farm Animals [Online]. Available: http://naldc.nal.usda.gov/download/CAT92970513/PDF
[14]Elevated Neutral-to-Earth Voltage, Urban Contact Voltage and Other Perceptibility Concerns for Humans and Animals [Online]. Available: http://strayvoltage.epri.com/index.asp

[15]G. Ahmadi and S. M. Shahrtash, "Neutral to earth voltage reduction methods in three-phase four wire distribution systems," in International Conference on Electrical and Electronics Engineering, Bursa, Turkey, 58 Nov., 2009, pp. I-134-I-138.

[16]T. C. Surbrook, N. D. Reese, and A. M. Kehrle, "Stray Voltage: Sources and Solutions," IEEE Transactions on Industry Applications, vol. IA-22, pp. 210-215, 1986.

[17]B. Jamali, R. Piercy, and P. Dick. Stray Voltage Mitigation [Online]. Available: http://www.ontarioenergyboard.ca/OEB/_Documents/EB 2007-0709/report_Kinectrics_20080530.pdf

[18] K. H. Chua, L. Yun Seng, P. Taylor, S. Morris, and W. Jianhui, "Energy Storage System for Mitigating Voltage Unbalance on Low-Voltage Networks With Photovoltaic Systems," IEEE Transactions on Power Delivery, vol. 27, pp. 1783-1790, 2012.

[19]O. C. Onar, M. Starke, G. P. Andrews, and R. Jackson, "Modeling, controls, and applications of community energy storage systems with used EV/PHEV batteries," in IEEE Transportation Electrification Conference and Expo, Dearborn, MI, USA, 18-20 Jun 2012, pp. 1-6.

[20]Community Energy Storage Systems: Meeting the Need for Energy Storage at the Grid's Edge [Online]. Available: http://www.sandc.com/edocs_pdfs/EDOC_070868.pdf

[21](January 2013). S\&C and Scottish and Southern Energy Power Distribution Announce Pilot Storage Project: UK Network Operator Installs First Energy Storage System on the Low Voltage Distribution Network [Online]. Available: http://www.sandc.com/news/index.php/2013/01/sc-and-scottish-andsouthern-energy-power-distribution-announce-pilot-storage-project/

[22](October 2012). Community Energy Storage for Grid Support: Demonstrating advanced implementation of community energy storage technologies for grid support [Online]. Available: http://energy.gov/sites/prod/files/DTE.pdf

[23]P. R. Thomas. (July 2011). American Electric Power Community Energy Storage [Online]. Available: https://www.smartgrid.gov/sites/default/files/doc/files/American_Electric _Power_Community_Energy_Storage_201109.pdf

[24]Functional Specification For Community Energy Storage (CES) Unit Revision 2.2 [Online]. Available: http://www.dolantechcenter.com/Focus/DistributedEnergy/docs/CESUnit Specifications_rev2_2.pdf

[25]W. Baochao, M. Sechilariu, and F. Locment, "Intelligent DC Microgrid With Smart Grid Communications: Control Strategy Consideration and Design," IEEE Transactions on Smart Grid, vol. 3, pp. 2148-2156, 2012.

[26]L. Xiong, W. Peng, and L. Poh Chiang, "A Hybrid AC/DC Microgrid and Its Coordination Control," IEEE Transactions on Smart Grid vol. 2, pp. 278-286, 2011.

[27]PID tuning algorithm for linear plant model [Online]. Available: http://www.mathworks.com.au/help/control/ref/pidtune.html

[28]M. J. E. Alam, K. M. Muttaqi, and D. Sutanto, "A Three-Phase Power Flow Approach for Integrated 3-Wire MV and 4-Wire Multigrounded LV Networks With Rooftop Solar PV," IEEE Transactions on Power Systems, vol. 28, pp. 1728-1737, 2013.

[29] A. D. Kolagar, P. Hamedani, and A. Shoulaie, "The effects of transformer connection type on voltage and current unbalance propagation," in Power Electronics and Drive Systems Technology, Tehran, Iran, 15-16 Feb., 2012, pp. 308-314.

[30]NREL. 1-Second Global Horizontal Irradiance Oahu, Hawaii [Online]. Available: http://www.nrel.gov/midc/oahu_archive/

\section{BIOGRAPHIES}

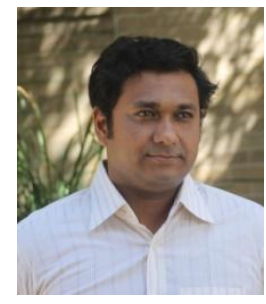

M J E Alam (M'14) received B.Sc. and M.Sc. Degree in Electrical and Electronic Engineering from Bangladesh University of Engineering and Technology, Dhaka, Bangladesh, in 2005 and 2009, respectively. In 2014, he obtained $\mathrm{PhD}$ degree in electrical engineering from the University of Wollongong, New South Wales, Australia, where he worked as an Associate Research Fellow. 
Currently he is working as a Postdoctoral Research Fellow at Global Change Institute, The University of Queensland, Australia. His research interest includes modeling and analysis of power systems with focus on renewable energy resources. He has also worked in the electric power industry in Bangladesh.

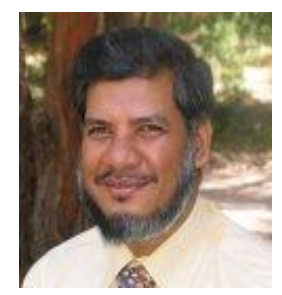

K M Muttaqi (M'01, SM'05) received the B.Sc. degree in electrical and electronic engineering from Bangladesh University of Engineering and Technology (BUET), Bangladesh in 1993, the M.Eng.Sc. degree in electrical engineering from University of Malaya, Malaysia in 1996 and the $\mathrm{Ph} . \mathrm{D}$. degree in Electrical Engineering from Multimedia University, Malaysia in 2001. Currently, he is an Associate Professor at the School of Electrical, Computer, and Telecommunications Engineering, and member of Australian Power Quality and Reliability (APQRC) at the University of Wollongong, Australia. He was associated with the University of Tasmania, Australia as a Research Fellow/Lecturer/Senior Lecturer from 2002 to 2007, and with the Queensland University of Technology, Australia as a Research Fellow from 2000 to 2002. Previously, he also worked for Multimedia University as a Lecturer for three years. He has more than 18 years of academic experience and has authored or coauthored around 200 papers in international journals and conference proceedings. His research interests include distributed generation, renewable energy, electrical vehicles, smartgrid, power system planning and control. Dr. Muttaqi is an Associate Editor of the IEEE TRANSACTIONS ON INDUSTRY APPLICATIONS.

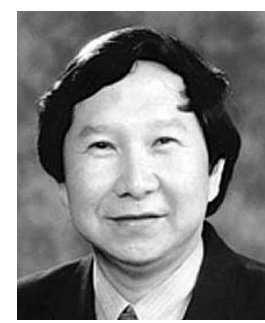

D Sutanto (SM'89) obtained his BEng. (Hons) and $\mathrm{PhD}$ from the University of Western Australia. He is presently the Professor of Power Engineering at the University of Wollongong, Australia. His research interests include power system planning, analysis and harmonics, FACTS and Battery Energy Storage systems. He is a Senior Member of IEEE. He is currently the IEEE IAS Area Chair for Region 10 (East South Asia and Pacific). 